\section{Evidence for an addition to the reading scan hypothesis*}

\section{SCHISSLER $\uparrow$, University of Wisconsin-Parkside, Kenosha, Wisconsin 53140 and \\ M. BARATTA, Northeastern University, Boston, Massachusetts 02115}

Letters were tachistoscopically presented in pairs to the left or right of fixation for 40 msec. The pair consisted of a target letter (B, D, P, or T) and a noise letter (all other letters of the alphabet except I), with the noise letter appearing either to the inside or the outside of the stimulus letter. S's task was to report verbally the target letter as fast as possible. Reaction times and number of errors indicated that there was more interference when the noise letter occurred further from the fixation point than the target letter for both the left and right visual field. Since a reading scan cannot account for the results in the right visual field, an outside-toward-fixation scan is proposed. An analysis of the different kinds of errors indicated that the outside to fixation scan is more primitive than the reading scan in that it produces less detailed information about the letters than does the reading scan.

It has been a common observation that when a series of letters are tachistoscopically presented in a horizontal array, the error curve is bow shaped, with relatively few errors occurring at the beginning and end of the letter sequence (Glanzer, 1966; Harcum, 1967). This beginning and end effect is relatively independent of retinal locus, showing up when the letters extend across the fixation point or occur to the left or right of the fixation (Crovitz \& Schiffman, 1965; Harcum, 1968). Harcum (1967, 1970) has proposed that this error curve is due to the same factors that produce serial error curves. He bases his argument on the assumption that a tachistoscopic array is sequentially scanned from left to right a number of times. In this way, the left-hand letter is recognized first (thus, reported most accurately) because of a primacy effect, while the right-hand letter is recognized faster than the middle letters because of the relative lack of conflicting associations for this letter.

Although Harcum's proposal seems to account for a row of letters, it cannot account for similar results with two-letter arrays. Mackworth (1965) found that placing an extraneous letter to the outside of two target letters located to the left and right of fixation produced about twice as many recognition errors as placing a noise letter inside the target letters. Mackworth suggested that "... the scanning of the visual image once it has been formed may be undertaken from the outside inward toward the

\footnotetext{
*A summary of this research was reported at the 1970 Psychonomic Society meetings.

TThe research was conducted while the senior author was at Northeastern University, Boston, Massachusetts 02115.
}

fovea [Mackworth, 1965, p. 68.]" Certainly, his results are incompatible with a left-to-right reading scan mechanism.

The present experiment was designed to study the type of scanning that occurs in a two-letter tachistoscopic presentation. It was hypothesized that letters presented to the left of fixation would show results reflecting a left-to-right scan since both an outside-toward-fixation scan and a reading scan would work in a similar fashion. Letters to the right of fixation should show effects of both a left-to-right scan and an outside-toward-fixation scan.

\section{METHOD}

The capital letters $B, D, P$, and $T$ were used singly as target letters that were paired with a noise letter. The noise letters were all of the other capital letters in the alphabet except $I$. For each trial, a target letter and noise le $t$ ter were presented tachistoscopically for $\mathbf{4 0} \mathrm{msec}$ either to the left or to the right of a fixation point. The target letter was always $6 \mathrm{deg} 36 \mathrm{~min}$ to the left or right of fixation, but the noise letter could be either $5 \mathrm{deg} 46 \mathrm{~min}$ from the fixation or $7 \mathrm{deg} 26 \mathrm{~min}$ from the fixation. Thus, there were four possible stimulus conditions: (1) in the left outside (LO) condition, both letters were to the left of fixation, noise letter 7 deg $26 \mathrm{~min}$ left and target letter 6 deg 36 min left; (2) in the left inside (LI) condition, both letters were to the left of fixation, target letter $6 \mathrm{deg} 36 \mathrm{~min}$ left and noise letter $5 \mathrm{deg} 46 \mathrm{~min}$ left; (3) in the right inside (RI) condition, both letters were to the right of fixation, noise letter $5 \mathrm{deg} 46 \mathrm{~min}$ right and target letter $6 \mathrm{deg} 36 \mathrm{~min}$ right; and (4) in the right outside ( $R O)$ condition, both letters were to the right of fixation, target letter 6 deg 36 min right, noise letter $7 \mathrm{deg} 26 \mathrm{~min}$ right. Each target letter ( $B, D, P$, and $T$ ) appeared nine times in each of these four conditions, for a total of 144 trials per $S$. The noise letters were chosen randomly.

The Ss were shown examples of all the target letters and conditions before the experiment was started. They were instructed to say the stimulus letter as fast as they could and to ignore the noise letter. They were informed of their reaction time (RT) after each trial. A trial was initiated by the S's pushing a button when he was ready. Following the trial, the $\mathrm{E}$ read aloud and recorded the $R T$, reset the apparatus, changed the stimulus card, and informed the $S$ that he could initiate another trial. Ten practice trials were run before the 144 experimental trials.

\section{A Gerbrands two-field Harvard} tachistoscope (Model T2B-19), a Gerbrands electronic voice key, and a Hunter KlocKounter (Model 120A) were used in the experiment. The starting button was an SPDT microswitch, which, in one position, charged an electrolytic capacitor $(100 \mathrm{mF}$ at $25 \mathrm{~V} \mathrm{dc}$ ). When the button was pushed, the capacitor discharge activated a double closure reed relay (Magnecraft W 103 MPCS-31). One of the relay closures started the tachistoscope, while the other closure activated the voice key which, in turn, started the timer. A microphone was attached immediately below the viewing hood of the tachistoscope so that it was directly in front of the S's mouth. When the $S$ responded verbally, the signal from the microphone deactivated the voice key and stopped the timer. The letters were printed with a Leroy II lettering set (Pen Number 3) and were $1.15 \mathrm{~cm}$ (1 deg $6 \mathrm{~min}$ ) high $\times .76 \mathrm{~cm}(44 \mathrm{~min})$ wide. The preexposure and postexposure field had a small central fixation point.

\section{Subjects}

The Ss were six male and four female undergraduate and graduate students at Northeastern University. Seven of the Ss were right-handed and three were left-handed. There was no systematic difference in results between the left- and right-handed Ss.

\section{Hypotheses}

The reading scan hypothesis proposes a tendency to start at the left of verbal material and then to scan to the right. This hypothesis would predict that the LO condition should create more errors than the LI condition since the scan would start 
Table 1

Summary of Mean Reaction Times in Milli seconds for Correct and Error Responses

Individual

Stimulus Conditions

\begin{tabular}{lllll} 
Responses & LO & LI & RI & RO \\
\hline Correct & 664 & 518 & 586 & 574 \\
Error & 723 & 487 & 700 & 708 \\
\hline
\end{tabular}

Combined Conditions

\begin{tabular}{lcccc} 
& L & R & I & O \\
\hline Correct & 581 & 575 & 552 & 619 \\
Error & 689 & 704 & 638 & 718 \\
\hline
\end{tabular}

with the noise letter first. This should cause errors and interfere with a rapid response. For LI, the target letter would be scanned first, producing few errors and a rapid response. $A$ perceptual scan going from the outside of the visual field in toward the fixation would produce the same results as a reading scan for $L O$ and $L I$. However, the two types of scanning produce opposite hypotheses about the RI and RO conditions. The reading scan should produce many errors and slow RTs for RI, again because the scan hits the noise letter first. Few errors and fast RTs should be found for RO. The outside-to-inside scan, on the other hand, would predict many errors and slow RTs for RO with fewer errors and faster RTs for RI.

\section{RESULTS}

The mean RTs for correct and error responses are shown in Table 1. An analysis of variance on the RT data for correct responses showed a significant main effect for the $\mathrm{I}-\mathrm{O}$ conditions $[F(1,9)=37.28, p<.01]$, while the L-R condition did not show a significant effect. In addition to the main effect, there was a significant interaction between $\mathrm{I}-\mathrm{O}$ and $\mathrm{L}-\mathrm{R}$ $[F(1,9)=31.60, p<.01]$. It can be seen from Table 1 that the LO reaction time is much slower than the LI reaction time, while the $R I$ reaction time is slightly slower than the RO reaction time. There were no other significant effects.

The mean error RTs for LO, LI, RI, and $\mathrm{RO}$ were compared to the mean correct RTs for the same conditions (see top half of Table 1) using a chi-square test for independence of entries in a contingency table (an analysis of variance was not possible with the error RTs because of the small and irregular number of errors). The result was significant $\left(x^{2}=12.26\right.$, $\mathrm{df}=3, \mathrm{p}<.01$ ), indicating that mean error RTs do not show the same distribution across conditions as mean correct RTs. The largest deviation of observed and expected values occurred for the LI condition, with the correct
RT being larger than expected and the error RT being smaller than expected $\left(x^{2} \doteq 3.99\right.$ and 3.57 for correct and error RTs, respectively, for LI condition).

The individual $S$ 's data agree remarkably well with the group data. For example, all Ss made more errors and had a slower mean correct RT in the $O$ condition than the $I$ condition. Over the four conditions, 7 of our 10 Ss made most errors in the LO condition, with the RO condition second in errors, while the other three Ss had most errors in RO, with LO second. For the mean correct RT, all of the Ss were slowest in the LO condition. Six of the Ss had the second slowest $R T$ in the RI condition, while the other four Ss had the second slowest $R T$ in the RO condition.

Since the comparison between error and correct RTs indicated that the LI condition differed for errors and correct responses, the errors were analyzed further to determine the reason for the difference (see Table 2). It was hypothesized that the errors for the LI condition occurred because the $S$, in responding rapidly, said an incorrect target letter. When the $S$ took more time to respond, he could select the correct response. It can be seen from Table 2 that 9 of the 10 errors in the LI condition were due to incorrect target responses with fast RTs, as hypothesized. On the other hand, the other three conditions show slow RTs for the incorrect target-letter errors, indicating that the Ss had difficulty in processing the target letter sufficiently to be certain of its identity rather than that they were responding too rapidly. Inspection of the nothing-detected and noise responses for $\mathrm{LO}, \mathrm{RI}$, and $\mathrm{RO}$ also indicates that the cause of the Ss' difficulty in processing the target letter is different for these three conditions. For the LO condition, the fast $\mathrm{RT}$ for noise responses indicates that the noise letter was processed first and thereby disrupted the processing of the target letter. For the RI condition, the noise responses were slower, indicating that it was not a simple matter of this letter's being processed first, but instead, that the noise letter was sometimes more completely processed than was the target letter. This made the noise letter more readily available as a response and caused difficulty in correctly identifying the target letter. Finally, for the RO condition, the large number of nondetections and small number of noise responses indicates that there was not enough information from the noise letter to produce a noise response but that there was enough information from it to disrupt
Table 2

Mean RT in Milliseconds and Number of Different Types of Errors for Each Stimulus Condition

\begin{tabular}{lrrrr} 
& \multicolumn{3}{c}{ Stimulus } & \multicolumn{2}{c}{ Condition } \\
\cline { 2 - 5 } $\begin{array}{c}\text { Type } \\
\text { of Error }\end{array}$ & LO & LI & RI & RO \\
\hline $\begin{array}{l}\text { Nothing Detected } \\
\text { Number }\end{array}$ & 5 & 1 & 1 & 14 \\
$\begin{array}{l}\text { Noise Response } \\
\text { Number }\end{array}$ & 18 & 0 & 10 & 4 \\
Mean RT & 585 & - & 637 & 730 \\
$\begin{array}{l}\text { Incorrect Target Response } \\
\text { Number }\end{array}$ & 38 & 9 & 12 & 27 \\
Mean RT & 792 & 487 & 752 & 706 \\
Total Errors & 61 & 10 & 23 & 45 \\
\hline
\end{tabular}

the processing and selection of the target letter.

\section{DISCUSSION}

The results clearly show that there was some mechanism operating in this experiment other than or in addition to a reading scan. The left visual field results support the hypothesis of a perceptual scan that proceeds from left to right. However, the right visual field results were a mixed pattern of errors and RTs that could not be accounted for with a left to right scan but could be partially accounted for with an outside-to-fixation scan, since this scan would make the RO condition more difficult than the RI condition.

An alternative argument might be made that the right visual field results could be accounted for with a scan that started at the fixation and moved toward the outside of the material. The assumption made by this argument is that the noise letter is more disruptive when it is processed second because then it can disrupt the storage of the target letter in a manner similar to metacontrast. However, this argument does not seem to be valid since it would assume for the left visual field that the scan would go from right to left, which is exactly the opposite of the sequence of processing used by English readers (Harcum, 1967, 1968, 1970; Heron, 1957).

Although an outside-to-fixation scan can account for the difficulty the Ss had with the RO condition, it cannot account for the relative difficulty the Ss had with the RI condition. If only an outside-to-fixation scan were operating in the right visual field, the results should mirror the results of the left visual field, with $\mathrm{RI}$ as easy as $\mathrm{LI}$ and RO as difficult as LO. What the results show instead is that $R I$ is somewhat more difficult than $L I$, and $R O$ is somewhat easier than LO. The analysis of error types indicates that this might 
be due to a reading scan that is operating along with an outside-to-fixation scan in the right visual field, since there are a relatively large number of noise letter errors in the RI condition. The noise letter errors also suggest that the reading scan produces detailed information about the letters for both visual fields. The outside-to-fixation scan, on the other hand, does not seem to produce detailed information, since the error types that occur in the $\mathrm{RO}$ condition indicate a general disruption of letter processing rather than an intrusion of the noise letter.

The preceding analysis suggests that the outside-to-fixation scan may be a more primitive type of information detection system than the reading scan. This idea is similar to Heron's proposal ". . . that before the postexposural process operates discrimination of the stimulus materials must occur at some level in the system [Heron, 1957, p. 45]." His "postexposural process" is the same as the reading scan, while the mechanism that operates before this process could be equivalent to the primitive outside-to-fixation scan being suggested here.

\section{REFERENCES}

CROVITZ, H. \& SCHIFFMAN, H. Visual field and the letter span. Journal of Experimental Psychology, 1965, 70, 218-223.
GLANZER, M. Encoding in the perceptual (visual) serial position effect. Journal of Verbal Learning \& Verbal Behavior, $1966,5,92-97$.

HARCUM, E. Parallel functions of serial learning and tachistoscopic pattern perception. Psychological Review, 1967. 74, $51-62$

HARCUM, E. Perceptual serial-position curves with a frequently isolated element. American Journal of Psychology, 1968, 81, 334-346.

HARCUM, E. Defining shape for perceptual element-position curves. Psychological Bulletin, 1970, 74, 362-372.

HERON, W. Perception as a function of retinal locus and attention. American Journal of Psychology, 1957, 70, 38-48.

MACKWORTH, N. Visual noise causes tunnel vision. Psychonomic Science, $1965,3,67-68$.

(Accepted for publication January 17, 1972.) 